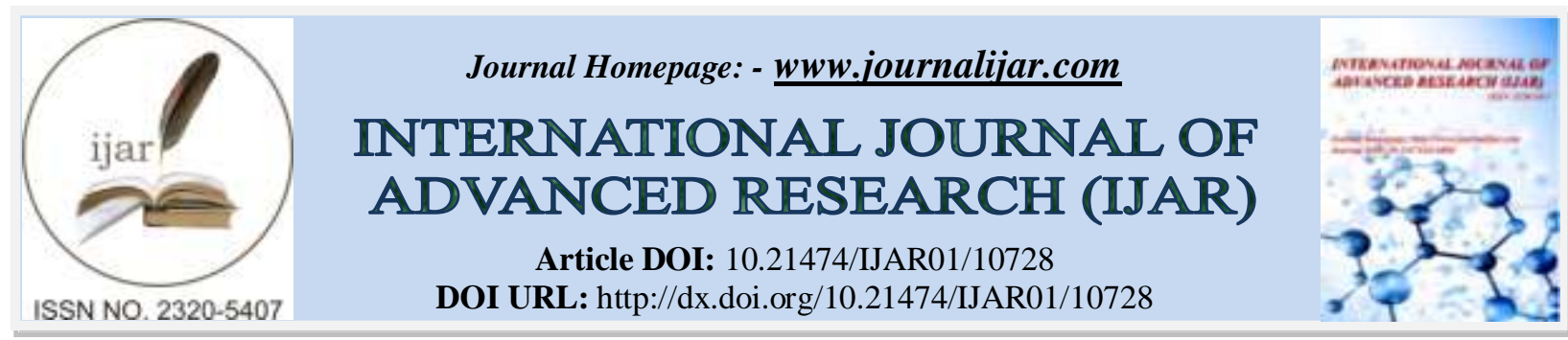

RESEARCH ARTICLE

\title{
IMPLICIT OF CONTRALATERAL EYE SURGERY IN ABERRANT REGENERATION OF OCULOMOTOR NERVE PALSY (OCULOMOTOR SYNKINESIS)
}

\author{
Dr. V Rajesh Prabu, MBBS, DNB, Dr. Rajlaxmi B Wasnik, MBBS, DOMS, Dr. Parul Priyambada, MBBS, \\ MS, DNB and Dr. Ranjini H, MBBS, DNB
}

Department of Pediatric Ophthalmology and Strabismus, Sankara Eye Hospital, Coimbatore, Tamil Nadu, India.

\section{Manuscript Info}

Manuscript History

Received: 25 January 2020

Final Accepted: 27 February 2020

Published: March 2020

Key words:-

Third Nerve Palsy, Aberrant

Regeneration, Strabismus, Diplopia,

Fixation Duress

\section{Abstract}

Aberrant regeneration of third nerve following its palsy is commonly seen after trauma and compressive lesions. Also known as Oculomotor Synkinesis, it refers to the abnormal response to firing of the oculomotor nerve causing paradoxical cocontraction(i.e. synkinesis) of muscles. It is a result of persistent partial oculomotor nerve dysfunction after failure to completely recover from disruption of the nerve due to any cause. Surgical management is a great challenge in the third nerve palsy due to multiple muscle involvement. We present a case of a 43-year-old male who developed complete third nerve palsy of the left eye following road traffic accident. He came one year after an accident with aberrant regeneration and diplopia. Patient underwent contralateral recession-resection surgery for accurate alignment of the eye, to improve diplopia and ptosis.

Copy Right, IJAR, 2020,. All rights reserved.

\section{Introduction:-}

\section{Case Report:}

A case of 43-yr-old male came to our hospital one year after road traffic accident with diplopia, abnormal deviation of the left eye, drooping of the left eyelid. On examination, best corrected Snellen's visual acuity in right eye was $6 / 6$ and in left eye 6/9 with both eye near vision N6. Anterior segment examination showed left eye ptosis with MRD 0 and mild chin lift. Left eye pupil was $4 \mathrm{~mm}$ fixed and dilated. On orthoptic evaluation, there was exotropia and hypotropia with complete restriction of elevation (-4), restriction of adduction(-1), restriction of depression(-2) in left eye( figure 1). On Prism bar cover test, left eye had 45PD exotropia for near and distance. Patient was having Aberrant regeneration features of inverse Duane's and Pseudo Von Graefe(figure 2). Patient had diplopia with maximum separation of crossed $L / R$ images in dextroversion and elevation and crossed $\mathrm{R} / \mathrm{L}$ images in depression. We did $8 \mathrm{~mm}$ lateral rectus recession and $5 \mathrm{~mm}$ medial rectus resection in contralateral right eye. Post operative day one, patient had residual exotropia with improvement in ptosis. Patient still had diplopia with minimal separation of images. We waited for three months. Patient underwent second surgery for diplopia and residual exotropia of 30PD with 5PD R/L. In left eye $8 \mathrm{~mm}$ lateral rectus recession with mild supraplacement was done. Patient was orthophoric after second surgery with improvement in ptosis and diplopia(figure 3).

Corresponding Author:- Dr. Rajlaxmi B. Wasnik

Address:- Department of Pediatric Ophthalmology and Strabismus, Sankara Eye Hospital, Coimbatore, Tamil Nadu, India. 


\section{Discussion:-}

Aberrant regeneration ${ }^{1}$ occur in partial recovery of oculomotor nerve. It occurs when damage happens from transection or disruption of endoneural integrity. Regenerating process produces more axons that were present before in peripheral motor, sensory nerve including autonomic nerve. Axons sprouts from proximal end of severed nerve and from collateral nerve that not have been severely damaged. In peripheral nerve that innervate more than one muscle, misdirection of regenerating nerve fibre may occur..Thus regenerating sprouts from axons that previously innervate one muscle group may ultimately innervate different muscle group with different function. In adults, evidence of synkinesis first appear about 9 weeks of injury. In infants it appears from birth trauma at about one to six weeks.

It is due to misdirection thus ${ }^{1}$, lateral palpebral superioris (LPS ) may receive fibers that were originally destined for medial rectus muscle or fibers intended for superior rectus may reach inferior oblique, inferior rectus, medial rectus. Adduction of involved eye on attempted elevation or depression, conversely elevation of eye on attempted adduction. (Inverse Duane's sign, Pseudo Von Graefe sign) is seen. Fibers originally destined for any of the muscle innervated by oculomotor nerve may reach ciliary ganglion to synapse with postganglionic parasympathetic fibers that innervate iris sphincter muscle, ciliary body muscle or both that causes the pupil to be nonreactive or react poorly, irregularly to light stimuli, although it may constrict on adduction during conjugate gaze. (Pseudo-Argyl-Robertson pupil). Other sign is limitation of elevation or depression of eye with occasional retraction of globe on attempted vertical movement.

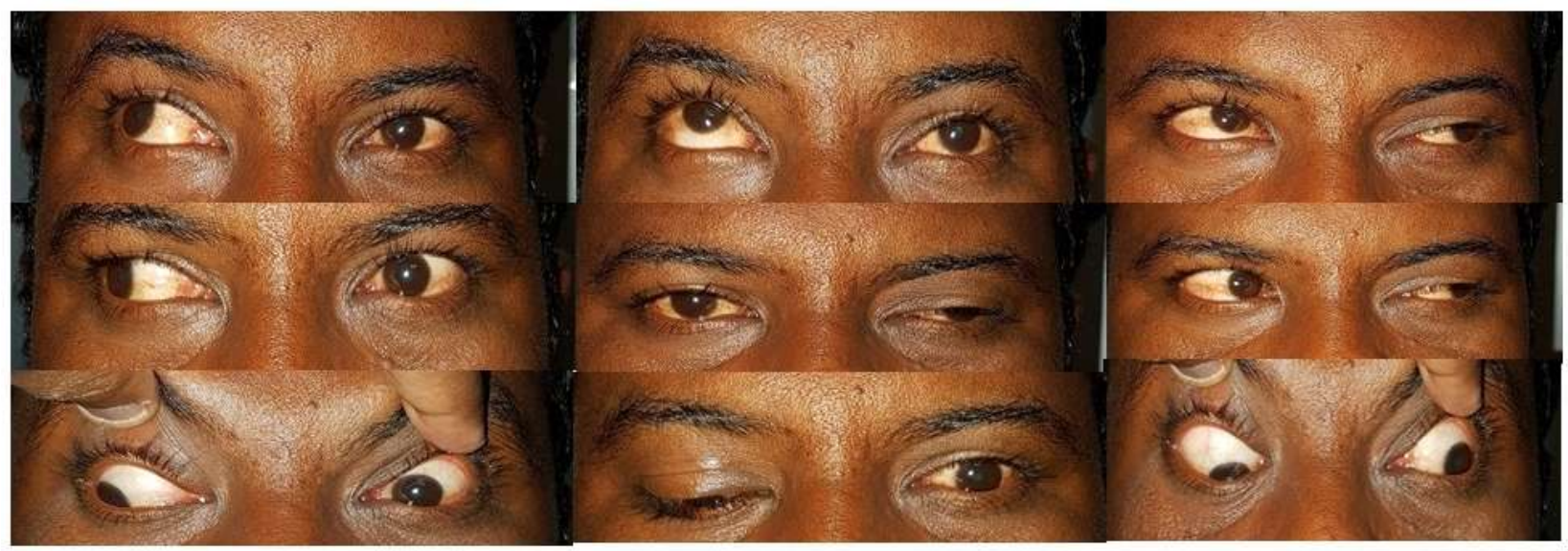

Figure 1: Nine gaze clinical photograph of the patient with left eye ptosis

Surgical management of oculomotor nerve palsy is difficult due to multiple muscle involvement in addition to the presence of ptosis. Misdirection to LPS muscle from medial rectus provides an opportunity to correct ptosis along with exotropia. Performing recession and resection procedure in the contralateral eye improves ptosis. This is $^{2}$ achieved by creation of fixation duress which is explained by Jamplosky. The fixation duress is proposed to decrease the elevation of non-involved eye, thereby creating similar forces of duress in both eyes when fixation takes place. Using this technique ${ }^{6}$, extra stimulus needed to elevate the fixing eye creates transference of neuromuscular stimuli to the yoke muscle in paretic eye in accordance with Hering's law. Thus affected eye medial rectus muscle pulling it in adducted position when fixing eye assumes fixation and ptotic eye gets elevated which sometimes helps in avoiding ptosis surgery due to the surgical technique which aims for the alignment of eyes in primary position.

There has been few case reports in the past where contralateral eye surgery has been done to correct strabismus along with ptosis. O'Donnell et $\mathrm{al}^{3}$ promoted the same surgery. Parulekar and Elston ${ }^{4}$ suggested large recession of lateral rectus and medial rectus resection, also downward transposition of insertion of medial and lateral recti to correct vertical deviation. Gottlob et $\mathrm{al}^{5}$ managed two cases of traumatic third nerve palsy with similar technique. 

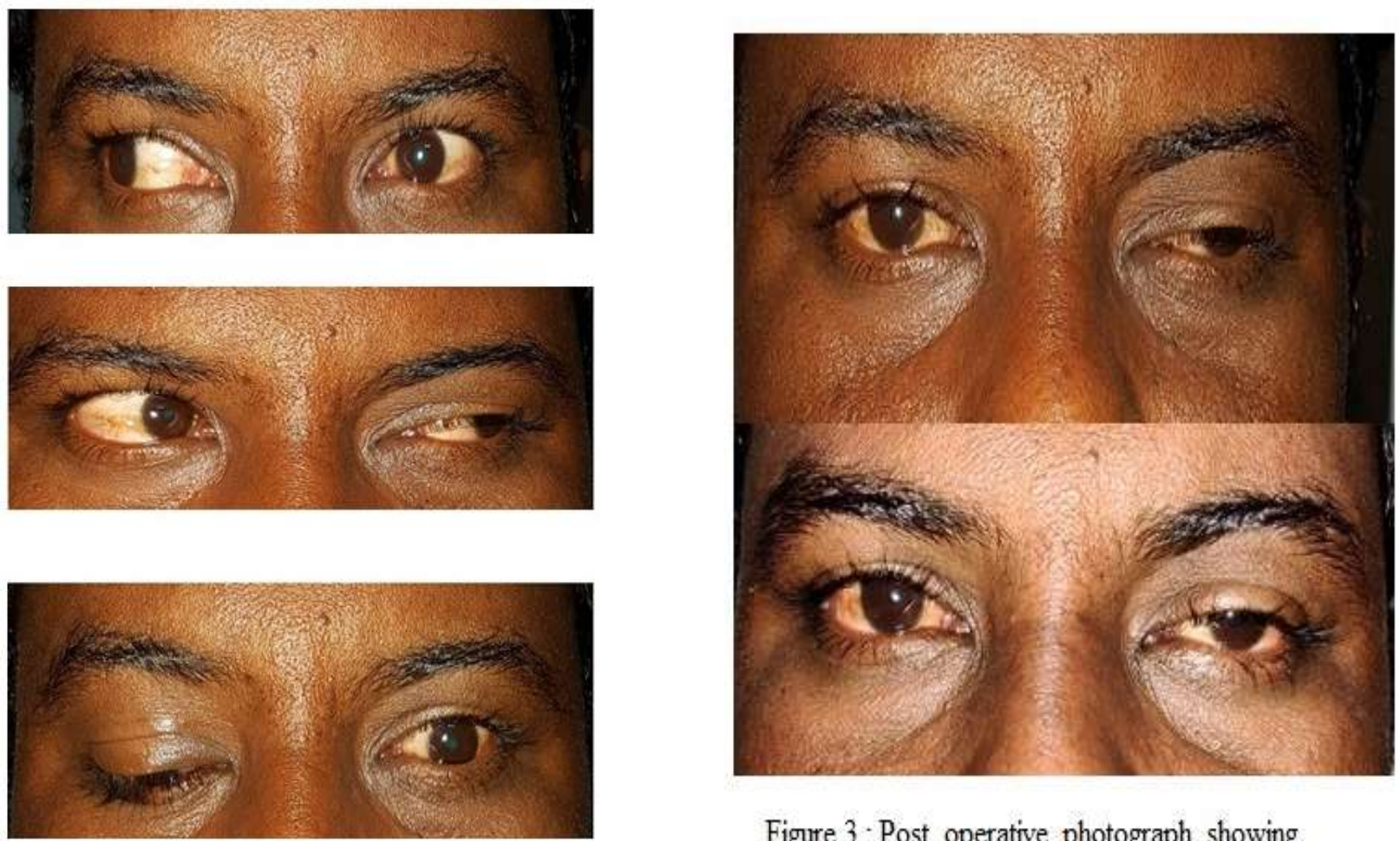

Figure 3 : Post operative photograph showing

Figure 2: Inverse Duane's and Pseudo Von Graefe sign improvement in ptosis

\section{Conclusion:-}

Traumatic oculomotor nerve palsy is mostly associated with aberrant regeneration of which most common are inverse Duane's and Pseudo-Von-Graefe signs. We aimed to achieve cosmetic correction in primary position with improvement of diplopia. Aberrant regeneration would be an opportunity to improve ptosis by performing horizontal muscle surgery in non-involved eye, thus obviating the need for ptosis surgery.

\section{References:-}

1. Walsh and Hoyt's ; clinical neuro-ophthalmology: The Essentials 3rd edition; 354-55

2. Carmel P Noonan, Martin O'Connor. British Journal of ophthalmology. 1997;79: 431-434

3. O'Donnell FE, Del Monte M, Guyton DL. Simultaneous correction of blepharoptosis and exotropia in aberrant regeneration of the oculomotor nerve by strabismus surgery: A new, simplified ptosis correction for selected cases. Ophthalmic Surg 1980;11:695-7

4. Parulekar MV, Elston JS. Surgery on paralytic eye for oculomotor palsy with aberrant regeneration. J Pediatric Ophthalmology Strabismus 2003;40:219-21

5. Gottlob I , Catalano RA, Reinecke RD. Surgical management of oculomotor nerve palsy. AM J Ophthalmology 1991;111:71-6

6. Phuong Thi Thanh NGUYEN, ShailjaTibrewal, Suma Ganesh. Contralateral eye surgery with adjustable suture for management of third nerve palsy with aberrant regeneration. Indian Journal of Ophthalmology 2017;65:10:1058-61. 